\title{
Analysis of biometric, physiological, and biochemical traits to evaluate the cadmium phytoremediation ability of eucalypt plants under hydroponics
}

\author{
Valentina lori ${ }^{(1)}$, \\ Fabrizio Pietrini ${ }^{(1)}$, \\ Daniele Bianconi ${ }^{(1)}$, \\ Giovanni Mughini (2), \\ Angelo Massacci ${ }^{(1)}$, \\ Massimo Zacchini ${ }^{(1)}$
}

\begin{abstract}
Wastewater reclamation and reuse represent a feasible solution to meet the growing demand for safe water. An environmentally sustainable technology such as phytoremediation is targeted for the reclamation of polluted waters. To this end, the capability of different plant species to tolerate and accumulate pollutants has to be investigated. In this work, eucalypt plants were studied by analysing biometric, physiological, and biochemical parameters related to cadmium (Cd) tolerance and accumulation in two clones ("Velino ex 7" and "Viglio ex 358") of Eucalyptus camaldulensis Dehnh. $\times E$. globulus subsp. bicostata (Maiden, Blakely \& J.Simm.) J.B. Kirkp exposed to $50 \mu \mathrm{M} \mathrm{CdSO}$ under hydroponics for three weeks. The results indicated that both eucalypt clones have a valuable tolerance to cadmium, expressed as the tolerance index (Ti). Biometric investigations showed that, regardless of the clone, the metal exposure affected most parameters related to biomass allocation and leaf growth. On the contrary, significant differences were found between the clones with respect to the chlorophyll content and the $\mathrm{Chl} a$ to $\mathrm{Chl} b$ ratio. These findings were also confirmed from the analysis of chlorophyll fluorescence transient (OJIP) using the JIP test. Cadmium accumulation occurred in both clones and in particular in the roots, with a poor amount of metal reaching the aerial parts, and the Velino clone showed the highest Cd accumulation. The metal uptake ratio and the phytoextraction efficiency highlight a good $\mathrm{Cd}$ phytoremoval ability, especially for the Velino clone. The results are discussed taking into account that, in wastewater phytoremediation systems, root biomass can be completely harvested allowing for the removal of the absorbed metal. Finally, the notable tolerance to submersion and the large environmental adaptability of eucalypt suggest that this plant species represents an interesting candidate for the phytoremediation of Cd-polluted wastewaters.
\end{abstract}

Keywords: Heavy Metals, Metal Tolerance, Wastewater, Forest Plants, Chlorophyll Fluorescence, Rhizofiltration

\section{Introduction}

Anthropogenic activities have led to the global degradation of the quality of surface and groundwater, thus representing a severe threat to the environment and human health. In this regard, cadmium (Cd) pollution is of special concern due to the high toxicity of this metal to biota, even at low concentrations, and its high solubility in water. Cadmium has no biological function in plant growth but it is readily taken up and accumulated in the edible parts of crops through the metabolic pathways of essential nutrient elements, especially $\mathrm{Zn}$ and $\mathrm{Fe}$, thus entering the human food chain, causing a wide variety of acute and
(1) Institute of Agro-environment and Forest Biology, National Research Council (CNR), v. Salaria Km. 29.300, 00015 Monterotondo Scalo (RM, Italy); (2) Research Unit for Intensive Wood Production, Council for Agricultural Research and Agricultural Economy Analysis (CREA), v. Valle della Quistione, 27, 00166 Roma (Italy)

@ Massimo Zacchini (massimo.zacchini@ibaf.cnr.it)

Received: May 30, 2016 - Accepted: Nov 11, 2016

Citation: Iori V, Pietrini F, Bianconi D, Mughini G, Massacci A, Zacchini M (2017). Analysis of biometric, physiological, and biochemical traits to evaluate the cadmium phytoremediation ability of eucalypt plants under hydroponics. iForest 10: 416-421. - doi: 10.3832/ifor2129-009 [online 2017-03-24]

Communicated by: Claudia Cocozza chronic toxic effects (Gallego et al. 2012).

Due to the world population increase, the demand for safe water represents a global challenge. Thus, appropriate management of the water resources is required. In this regard, wastewater reclamation and reuse problem of the water shortage related to crop irrigation. In many countries irrigation with raw wastewater is a commonly utilised agricultural practice, possibly causing the accumulation of metals in the soil and their transfer into food plants (Fatta-Kassinos et al. 2011). A considerable interest in the development of alternative wastewater management strategies, which are less expensive and more environmentally sustainable than conventional technologies, has been increasing. Biological approaches such as phytoremediation, i.e. the use of plants to clean up surface and groundwater contaminated by several pollutants, has received considerable attention because of its cost-effectiveness and environmentally friendly nature (Lu et al. 2011). In this context, interesting perspectives for the utilihas become an attractive solution to the 
sation of forest plants in the reclamation of polluted waters have been evidenced (Guidi Nissim et al. 2014, Pietrini et al. 2015).

Most studies on heavy metal tolerance and accumulation by forest plants have been focused on poplars and willows due to their deep and extensive root systems, fast growth, high evapo-transpiration rates, easy management, and low impact on trophic chains (Zacchini et al. 2009, Guidi Nissim et al. 2014). In contrast, little information is available in the literature about the phytoremediation potential of Eucalyptus spp., in particular for the reclamation of heavy metal contaminated waters.

The Eucalyptus genus includes over 500 species greatly adapted to an extremely wide range of environments and characterised by high genetic variability and economic value. In particular, Eucalyptus species have been reported to cope well with environmental constraints such as severe saline and drought conditions, maintaining high transpiration rates (Harfouche et al. 2014). Moreover, growth responses of eucalypt plants to the presence of heavy metals, both in laboratory and field conditions, have been described (Fine et al. 2013, Mughini et al. 2013), highlighting good perspectives for their utilisation for phytoremediation (Dhillon et al. 2008, Pietrini et al. 2015). To this scope, besides the adaptability to different pedoclimatic conditions, the selection of genotypes characterised by particular traits linked to metal tolerance and accumulation has been suggested (Pietrini et al. 2010, Zhivotovsky et al. 2011). In previous studies on forest trees, parameters such as the metal uptake ratio, translocation factor, tolerance index, and $\mathrm{Cd}$ content in the plant were highlighted as suitable to select genotypes for Cd tolerance and bioaccumulation (Zacchini et al. 2009, Iori et al. 2016). Furthermore, a correlation between physiological, biochemical, and molecular parameters and the phytoremediation capability of forest plants was recently assessed (Gaudet et al. 2011, lori et al. 2015). In this context, chlorophyll a fluorescence analysis represents a useful tool to analyze the changes at the physiological and biochemical level in the photosynthetic apparatus under variable environmental conditions (Cocozza et al. 2014). Specifically, OJIP fluorescence transient analysis, known as the JIP test (Strasser et al. 2004), has been developed for the quantification of several phenomenological and biophysical expressions together with the energy flux parameters of photosystem II (PS II), and may be used to assess metal stress in vivo (Singh \& Prasad 2015). Up to now, no works dealing with $\mathrm{Cd}$ tolerance in eucalypt plants were using the JIP test. This novel approach could be of relevance for a successful screening of plant materials for phytoremediation. Finally, hydroponic screening has been proposed as a rapid and suitable technique for testing the phytoremediation ability of woody plants, especially for metal removal in aqueous matrices (Pietrini et al. 2010, Zhivotovsky et al. 2011).

The aim of this study was to investigate the metal tolerance, accumulation, and organ distribution in two hybrid clones of Eucalyptus camaldulensis Dehnh. $\times$ E. globulus subsp. bicostata (Maiden, Blakely \& J.Simm.) J.B. Kirkp. exposed to $\mathrm{Cd}$ under hydroponics, by analyzing the growth responses, chlorophyll and metal content, and chlorophyll fluorescence parameters in order to evaluate their phytoremoval capabilities for Cd-polluted waters. Due to the remarkable ability to grow under partial submersion and the large environmental adaptability of eucalypt plants, the assessment of the metal phytoremoval ability represents the crucial step in order to exploit this plant material as a bio-tool for phytoremediation. Particularly, the possibility to use this forest species for water reclamation could open up interesting perspectives for the phytodepuration of wastewater for agricultural purposes, especially in countries that are currently experiencing water scarcity.

\section{Materials and methods}

\section{Plant material and growth conditions}

One-year-old rooted cuttings of two eucalypt hybrid clones Eucalyptus camaldulensis Dehnh. $\times$ E. globulus subsp. bicostata (Maiden, Blakely \& J.Simm.) J.B. Kirkp., named Velino and Viglio (Mughini et al. 2013), were grown during summer under shaded greenhouse in hydroponics with thirdstrength Hoagland's nutrient solution, $\mathrm{pH}$ 6.5. Homogeneous grown plants were utilised for the experiment. Five plants were assigned to each 9 liter pot filled with 0 (control) or $50 \mu \mathrm{M} \mathrm{CdSO}_{4}$ in third-strength Hoagland's nutrient solution, $\mathrm{pH}$ 6.5, and cultivated for three weeks in greenhouse under natural photoperiod, with mean temperatures of $22-25{ }^{\circ} \mathrm{C}$ (night-day) and relative humidity of $60-70 \%$. The $\mathrm{Cd}$ concentration was chosen in accordance with previous studies which evaluated the Cd phytoremediation potential of forest plant species (Zacchini et al. 2009, Pietrini et al. 2010). Pots were provided with a pumping system to avoid oxygen deprival and the nutrient solution was replaced twice a week to maintain initial metal concentration and prevent nutrient depletion. At the end of the experiment, control and treated plants were harvested and washed with distilled water without damaging the roots. After biometric and physiological measurements, plant organs were separated and dried in an oven at $80^{\circ} \mathrm{C}$ until a constant weight.

\section{Biometric parameter evaluation}

Biomass data were utilised for the calculation of different biometric parameters. The tolerance index $(\mathrm{Ti})$ was calculated as the ratio of the dry weight of plant organs of Cd-treated plants to the dry weight of plant organs of control plants. Leaf area was measured using the Leaf Area Meter Li-3000 (Licor, NE, USA). The specific leaf weight (SLW) was calculated as the ratio of the leaf mass relative to the leaf area. The specific leaf area (SLA) was calculated as the ratio of the leaf area relative to the leaf mass.

The calculation of the organ mass ratio was performed as the ratio of the leaf (LMR), stem (SMR) and root (RMR) biomass to the total plant biomass.

\section{Chlorophyll content determination and chlorophyll fluorescence analysis (JIP test)}

Two $\mathrm{cm}^{2}$ of the last fully expanded leaf, sampled at the end of the experiment, were extracted in $80 \%$ chilled acetone in the dark. After centrifugation at $10,000 \times \mathrm{g}$ for $10 \mathrm{~min}$, absorbance of the supernatant was measured at 646.8 and $663.2 \mathrm{~nm}$. The content of chlorophyll $a$ and $b$ was estimated as described by Lichtentaler (1987).

At the end of the treatment, the chlorophyll a fluorescence transient (OJIP transients) was measured on the last fully expanded leaves of both eucalypt clones, using a Plant Efficiency Analyser (PEA, Hansatech Instruments Ltd., King's Lynn, UK). The measurements were performed on leaves that were previously adapted to the dark for 60 minutes for the complete oxidation of the photosynthetic electron transport system, and the fluorescence intensity was measured for $1 \mathrm{~s}$ after the application of a saturating light pulse of $3000 \mu \mathrm{mol} \mathrm{m} \mathrm{m}^{-2} \mathrm{~s}^{-1}$. The JIP-test was employed to analyse OJIP transient and bioenergetics parameters: size and number of active reaction centre of photosynthetic apparatus $\left(F_{v} / F_{0}\right)$, efficiency of water splitting complex $\left(F_{o} / F_{v}\right)$, quantum yield of primary photochemistry $\left(F_{v} / F_{m}\right.$ or $\left.\phi P_{0}\right)$, performance index of PS II $\left(\mathrm{PI}_{\mathrm{ABS}}\right)$ were determined as described by Strasser et al. (2004).

\section{Cadmium content analysis}

Cadmium concentration was measured using an atomic absorption spectrophotometer (Perkin Elmer, Norwalk, CT, USA) on digested samples. Dried material was milled to a fine powder (Tecator Cemotec 1090 Sample Mill - Tecator, Hoganas, Sweden), weighed and mineralised as reported elsewhere (lori et al. 2015).

The metal uptake ratio describes the capability of the plant to extract and accumulate $\mathrm{Cd}$ and it was calculated as the ratio of the $\mathrm{Cd}$ content in the whole plant to the $\mathrm{Cd}$ content of the corresponding growth solution (Iori et al. 2013).

The metal translocation index describes the ability of the plant to translocate the metal and it was measured as the ratio of the $\mathrm{Cd}$ content of the aerial parts (leaves and stem) to the Cd content of the corresponding roots (Iori et al. 2013).

The metal content in plant parts was calculated by multiplying the dry weight by 
the metal concentration.

The metal phytoextraction efficiency (mg $\left.\mathrm{g}^{-1}\right)$ was calculated according to Wang et al. (2007) as the ratio of the $\mathrm{Cd}$ amount in the aerial parts (leaves and stem, $\mathrm{mg}$ plant ${ }^{-1}$ ) to the corresponding root biomass (g DW plant $\left.^{-1}\right)$.

\section{Statistical analysis}

The data reported refer to a single typical experiment with five replicates. Normally distributed data were processed with a one or two-way analysis of variance (ANOVA), depending on the number of the factors of variability, using the software SPSS $^{\circledast}$ (Chicago, IL, USA). Statistical significance of the differences between means was assessed by Duncan's test $(P \leq 0.05)$, unless otherwise stated.

\section{Results and discussion}

Metal tolerance is a basic factor affecting the efficiency of the phytoremediation processes, and its evaluation represents a step of the utmost importance in plant screening for phytoremediation purposes (Zacchini et al. 2009). In this study, the ability of both eucalypt clones to grow under $\mathrm{Cd}$ exposure was analyzed by calculating the $\mathrm{Ti}$ (Tab. 1). On the basis of the total plant dry mass, the Ti revealed a remarkable difference in $\mathrm{Cd}$ tolerance between the two clones, resulting in far higher tolerance in the Velino clone. With respect to plant organs, no differences between the two eucalypt clones were detected at the stem and leaf level, whereas at the root level the Velino clone showed a higher tolerance to $\mathrm{Cd}$ than the Viglio clone. Overall, a notable tolerance to the metal was observed in the two eucalypt clones. Therefore, according to the scheme proposed by Lux et al. (2004), these clones could be defined as highly tolerant (Velino, $\mathrm{Ti}>60$ ) and moderately tolerant (Viglio, Ti between 35 and 60). This finding appears of particular interest given the high $\mathrm{Cd}$ concentration of the spiked water used in this work which was set at about 2000 times higher than that allowed by the Italian Law for underground waters.

The variation of the biomass allocation among organs is considered a suitable parameter which contributes to the efficient selection of plants to be used in phytoremediation applications. In this work, control plants showed a similar trend in biomass partitioning (Tab. 2), allocating most of the dry mass in the roots, followed by leaves and stems. Although no differences between the two clones were observed upon metal treatment, $\mathrm{Cd}$ exposure caused a decrease in RMR, which was around $65 \%$ compared to the control, and a slight increase in SMR and LMR. Consistent with this data, a reduction of the RMR in plants treated with metals was previously reported by Vassilev et al. (1998) for Cd and by lori et al. (2013) for $\mathrm{Ni}$, as the result of their toxicity effect on plant growth. Root growth is considered a useful parameter

Tab. 1 - Tolerance index $(\mathrm{Ti})$ in plant organs and total plant of two eucalypt hybrid clones treated in hydroponics for three weeks with $50 \mu \mathrm{M} \mathrm{CdSO}_{4}$. Data are mean values \pm standard error $(n=5)$. Different letters in the same column indicate significantly different values after $t$-test $(P \leq 0.05)$.

\begin{tabular}{lcccc}
\hline Clone & Roots & Stem & Leaves & Total plant \\
\hline Velino & $0.68 \pm 0.08^{\mathrm{a}}$ & $0.72 \pm 0.11$ & $0.89 \pm 0.14$ & $0.70 \pm 0.11^{\mathrm{a}}$ \\
Viglio & $0.44 \pm 0.14^{\mathrm{b}}$ & $0.59 \pm 0.11$ & $0.72 \pm 0.16$ & $0.47 \pm 0.10^{\mathrm{b}}$ \\
\hline
\end{tabular}

Tab. 2 - Organ mass ratio ( $\mathrm{g} \mathrm{g}^{-1} \mathrm{DW}$ ) in plants of two eucalypt hybrid clones treated with o (C) and $50 \mu \mathrm{M} \mathrm{CdSO}_{4}(\mathrm{Cd})$ in hydroponics for three weeks. Data are mean values \pm standard error $(n=5)$. Different letters in the same column indicates significantly different values after Duncan test. $(* * *): P \leq 0.001 ;(n s)$ : not significant.

\begin{tabular}{llccc}
\hline Clone & Treatment & Root:mass & Stem:mass & Leaf:mass \\
\hline Velino & C & $0.42 \pm 0.01$ & $0.27 \pm 0.01$ & $0.31 \pm 0.01$ \\
& Cd & $0.29 \pm 0.02$ & $0.31 \pm 0.01$ & $0.38 \pm 0.03$ \\
Viglio & C & $0.41 \pm 0.02$ & $0.26 \pm 0.004$ & $0.32 \pm 0.01$ \\
& Cd & $0.27 \pm 0.21$ & $0.34 \pm 0.01$ & $0.38 \pm 0.41$ \\
$P$-value & Clone & ns & ns & ns \\
(ANOVA) & Treatment & $* * *$ & ns & ns \\
& Clone $\times$ Treatment & ns & ns & \\
\hline
\end{tabular}

Tab. 3 - Leaf biometric parameters in plants of two eucalypt hybrid clones treated with $\mathrm{o}(\mathrm{C})$ and $50 \mu \mathrm{M} \mathrm{CdSO}{ }_{4}(\mathrm{Cd})$ in hydroponics for three weeks. Data are mean values \pm standard error $(n=5)$. Different letters in the same column indicates significantly different values after Duncan test. $\left({ }^{*}\right): P \leq 0.05 ;(* * *): P \leq 0.001 ;(n s)$ : not significant.

\begin{tabular}{llccc}
\hline Clone & Treatment & $\begin{array}{c}\text { Leaf Area } \\
\left(\mathbf{c m}^{2}\right)\end{array}$ & $\begin{array}{c}\text { Specific Leaf Weight } \\
\left(\mathrm{SLW}, \mathbf{g ~ c m}^{-2}\right)\end{array}$ & $\begin{array}{c}\text { Specific Leaf Area } \\
\left(\mathrm{SLA}, \mathbf{c m}^{2} \mathbf{g}^{-1}\right)\end{array}$ \\
\hline Velino & $\mathrm{C}$ & $148.6 \pm 17.8$ & $0.0284 \pm 0.0026$ & $37.4 \pm 1.6^{\mathrm{ab}}$ \\
& Cd & $131.5 \pm 9.4$ & $0.0269 \pm 0.0031$ & $35.3 \pm 1.1^{\mathrm{b}}$ \\
Viglio & $\mathrm{C}$ & $175.2 \pm 17.1$ & $0.0285 \pm 0.0042$ & $35.4 \pm 1.7^{\mathrm{b}}$ \\
& Cd & $161.4 \pm 16.6$ & $0.0235 \pm 0.0052$ & $43.6 \pm 3.5^{\mathrm{a}}$ \\
P-value & Clone & $*$ & $\mathrm{~ns}$ & $\mathrm{~ns}$ \\
(ANOVA) & Treatment & $* * *$ & $*$ & $\mathrm{~ns}$ \\
& Clone $\times$ Treatment & $\mathrm{ns}$ & $\mathrm{ns}$ & $*$ \\
\hline
\end{tabular}

for metal tolerance tests, as the root apparatus is the first plant organ in close contact with the metal and it is the primary site of metal toxic action (Lux et al. 2004). The reduction of biomass allocation observed in the roots of both eucalypt clones can be ascribed to the disturbance of micronutrient uptake and oxidative stress induction by the metal, thus leading to the inhibition of root cell division and an increase in the lignification, as suggested by several authors (Vassilev et al. 2005, Zhivotovsky et al. 2011, Stoláriková et al. 2012).

When $\mathrm{Cd}$ is taken up by the roots, it may be translocated to the aerial parts of the plant via xylem reaching the leaf apparatus. At the leaf level, the damaging effects caused by $\mathrm{Cd}$ are particularly targeted in plants screened for phytoremediation. In fact, an efficient photosynthetic machinery allows plants to maintain an effective transpiration flux that drives metal translocation to the aerial parts (Pietrini et al. 2010). In the present study, the effect of $\mathrm{Cd}$ on the leaves of eucalypt plants was analysed by measuring biometric and biochemical parameters such as the total leaf area, the
SLW and SLA (Tab. 3), and the chlorophyll content (Tab. 4). Concerning the total leaf area, differences between the two clones were observed in the control plants, and this parameter was higher in the Viglio clone. Consistent with the findings of several authors (Vassilev et al. 1998, Zacchini et al. 2009), even though on different plant species, the $\mathrm{Cd}$ treatment caused a reduction of the leaf area in the eucalypt clones, but no differences between the two clones were observed. Contrarily, Cocozza et al. (2015) reported a lack of modification of the leaf area in a poplar clone exposed to Cd. Regarding the SLW, irrespective of the clone, the $\mathrm{Cd}$ exposure reduced the mass of the leaf unit, as previously reported by Sharma et al. (2008) in carrot plants exposed for a long time period to $\mathrm{Cd}$ and $\mathrm{Zn}$. Regarding the SLA, no differences between the two clones were observed in the control plants, however under Cd treatment this parameter differed significantly between the two clones, resulting in a higher SLA for the Viglio clone. No differences between the control and treated plants were observed in the Velino clone, confirming the reduced sensitivity to $\mathrm{Cd}$ 
Tab. 4 - Chlorophyll content and chlorophyll ratio evaluated in plants of two eucalypt hybrid clones treated with $\mathrm{O}$ (C) and $50 \mu \mathrm{M} \mathrm{CdSO}_{4}$ (Cd) in hydroponics for three weeks. Data are mean values \pm standard error $(n=5)$. Different letters in columns indicate significantly different values after Duncan's test. $(* *): P \leq 0.01 ;(* * *): P \leq 0.001$; (ns): not significant.

\begin{tabular}{llcccc}
\hline Clone & Treatment & $\begin{array}{c}\mathrm{Chl} a \\
\left(\mu \mathrm{g} \mathrm{cm}^{-2}\right)\end{array}$ & $\begin{array}{c}\mathrm{Chl} \mathrm{b} \\
\left(\mu \mathrm{g} \mathrm{cm}^{-2}\right)\end{array}$ & $\begin{array}{c}\text { Tot Chl } \\
\left(\mu \mathrm{cm}^{-2}\right)\end{array}$ & Chl $a / \mathrm{Chl} b$ \\
\hline Velino & $\mathrm{C}$ & $21.08 \pm 0.53^{\mathrm{a}}$ & $6.57 \pm 0.16^{\mathrm{a}}$ & $27.65 \pm 0.60^{\mathrm{a}}$ & $3.2070 \pm 0.0005^{\mathrm{a}}$ \\
& $\mathrm{Cd}$ & $14.54 \pm 0.60^{\mathrm{b}}$ & $4.55 \pm 0.18^{\mathrm{b}}$ & $19.09 \pm 0.79^{\mathrm{b}}$ & $3.1890 \pm 0.0053^{\mathrm{b}}$ \\
Viglio & $\mathrm{C}$ & $22.79 \pm 0.89^{\mathrm{a}}$ & $7.11 \pm 0.28^{\mathrm{a}}$ & $29.91 \pm 1.17^{\mathrm{a}}$ & $3.2034 \pm 0.0016^{\mathrm{ab}}$ \\
& $\mathrm{Cd}$ & $11.99 \pm 0.71^{\mathrm{c}}$ & $3.79 \pm 0.21^{\mathrm{c}}$ & $15.79 \pm 0.92^{\mathrm{c}}$ & $3.1533 \pm 0.0102^{\mathrm{c}}$ \\
\hline P-value & Clone & $\mathrm{ns}$ & $\mathrm{ns}$ & $\mathrm{ns}$ & $* * * *$ \\
(ANOVA) & Treatment & $* * *$ & $* * *$ & $* * *$ & $* * *$ \\
& Clone $\times$ & $* * *$ & $* * *$ & $* *$ & $*$ \\
& Treatment & & & & \\
\hline
\end{tabular}

Tab. 5 - Leaf chlorophyll fluorescence parameters, size and number of active reaction centre of photosynthetic apparatus $\left(F_{v} / F_{0}\right)$, efficiency of water splitting complex $\left(F_{0} / F_{v}\right)$, quantum yield of primary photochemistry $\left(F_{v} / F_{m}, \phi P_{o}\right)$, performance index of PS II ( $\left(\mathrm{PI}_{\mathrm{ABS}}\right)$ evaluated in control (C) and in $50 \mu \mathrm{M} \mathrm{CdSO}{ }_{4}(\mathrm{Cd})$ treated cuttings of two eucalypt hybrid clones in hydroponics for three weeks. Data are mean values \pm standard error $(n=5)$. Different letters in columns indicate significantly different values after Duncan's test. $\left({ }^{*}\right)$ : $P \leq 0.05 ;(* *): P \leq 0.01 ;(* * *): P \leq 0.001 ;(n s)$ : not significant.

\begin{tabular}{llcccc}
\hline Clone & Treatment & $\mathbf{F}_{\mathrm{v}} / \mathrm{F}_{0}$ & $\mathbf{F}_{0} / \mathbf{F}_{\mathrm{v}}$ & $\mathbf{F}_{\mathrm{v}} / \mathrm{F}_{\mathrm{m}}\left(\phi \mathrm{P}_{0}\right)$ & $\mathrm{Pl}_{\mathrm{ABS}}$ \\
\hline Velino & $\mathrm{C}$ & $3.86 \pm 0.08$ & $0.259 \pm 0.005$ & $0.793 \pm 0.003$ & $13.98 \pm 0.72^{\mathrm{a}}$ \\
& $\mathrm{Cd}$ & $2.61 \pm 0.09$ & $0.392 \pm 0.015$ & $0.719 \pm 0.007$ & $4.97 \pm 0.39^{\mathrm{b}}$ \\
Viglio & $\mathrm{C}$ & $3.63 \pm 0.08$ & $0.277 \pm 0.006$ & $0.783 \pm 0.003$ & $13.16 \pm 0.62^{\mathrm{a}}$ \\
& $\mathrm{Cd}$ & $2.35 \pm 0.10$ & $0.430 \pm 0.020$ & $0.701 \pm 0.010$ & $2.22 \pm 0.21^{\mathrm{c}}$ \\
P-value & Clone & ${ }^{*}$ & $\mathrm{~ns}$ & ${ }^{*}$ & ${ }^{* *}$ \\
(ANOVA) & Treatment & ${ }^{* *}$ & ${ }^{* * *}$ & ${ }^{* * *}$ & ${ }^{* * *}$ \\
& Clone $x$ Treatment & $\mathrm{ns}$ & $\mathrm{ns}$ & $\mathrm{ns}$ & ${ }^{*}$ \\
\hline
\end{tabular}

expressed by this clone at the morphological level. A lack of modification of the SLA in forest plant species treated with heavy metals was also found by Borghi et al. (2007).

Eucalypt clones showed similar values for chlorophyll $a, b$, and total chlorophyll content in the control plants, while in $\mathrm{Cd}$ treated plants a reduction of these pig ments was particularly appreciable in the Viglio clone (Tab. 4). Vassilev et al. (2005) suggested that the decrease in chlorophyl content in the leaves of Cd-treated plants might be a consequence of metal-induced enzymatic degradation as well as mineral deficiency. In addition, the $\mathrm{Chl} a / b$ ratio was altered by $\mathrm{Cd}$ treatment. In fact, this ratio was decreased in both clones compared with the control, but this decrease was higher in plants of the Viglio clone (Tab. 4). This reduction was probably due to a faster degradation of $\mathrm{Chl} a$ compared with $\mathrm{Chl} b$ under $\mathrm{Cd}$ stress in the Viglio clone (Kummerová et al. 2010). Since the $\mathrm{Chl} a / b$ ratio is an indicator of both the functional pigment equipment and the light adaptation/ acclimation of the photosynthetic apparatus, monitoring its decrease can be used as an early warning system for the toxic effects of metal accumulation in plants (Li et al. 2009). In this regard, Cd induced toxicity on eucalypt plants can also be evaluated by investigating the photochemistry of PS II through the analysis of the chlorophyll fluorescence kinetics (JIP test - Tab. 5). Cadmium treatment decreased $F_{v} / F_{m}\left(\phi P_{0}\right)$, as well as $F_{v} / F_{0}$, and increased $F_{0} / F_{v}$ to the same extent in both clones, highlighting the impairment of PSII. Comparable results were also found by Singh \& Prasad (2015) and by Li et al. (2015) respectively, in Solanum melongena $\mathrm{L}$. and in Elsholtzia argyi $\mathrm{L}$. plants exposed to different $\mathrm{Cd}$ concentrations, while Cocozza et al. (2014) observed that the photochemical efficiency was not affected by $\mathrm{Cd}$ addition in a poplar clone. The ratio of $F_{v} / F_{m}$ is usually used as a stress indicator, representing the maximum quantum yield of PS II photochemistry, while $F_{v} / F_{0}$ indicates the size and number of active photosynthetic centers in the chloroplast and, therefore, the photosynthetic strength of the plant. As reported by Mallick \& Mohn (2003), a reduction in the $F_{v} / F_{m}$ ratio may occur if re-oxidation of the quinone $\mathrm{Q}_{A}$ was limited by a decrease or partial block of electron transport from PS II to PS I. Moreover, a decline in the $F_{v} / F_{0}$ ratio may indicate a PS II donor side inhibition connected with modification of the thylakoid membrane structure (Krupa \& Baszynski 1995) or a reduction of the pool size of $\mathrm{Q}_{A}$ associated with PS II activity (Krause \& Weis 1991). Specifically, as reported by Dan et al. (2000), the reduction of the $F_{v} / F_{0}$ ratio in Helianthus annuus plants exposed to $\mathrm{Cd}$ indicated a change in the rate of electron transport from PS II to the primary electron acceptors. The $F_{0} / F_{v}$ ratio represents the efficiency of the water-splitting apparatus of the PS II and reflects its state (Kriedemann et al. 1985). As reported by Mallick \& Mohn (2003), a notable increase in the $F_{o} / F_{v}$ suggests that $C d$ had a severe impact on the water-splitting site, most probably by replacing manganese from the water-splitting apparatus of the oxidizing side, resulting in a disruption of the photosynthetic reactions. Moreover, Gonzalez-Mendoza et al. (2007) suggested that the changes in the chlorophyll fluorescence parameters $\left(F_{v} / F_{m}, F_{v} / F_{0}\right.$, and $\left.F_{0} / F_{v}\right)$ induced by $\mathrm{Cd}$ treatment could be the result of a $\mathrm{Ca}^{2+}$ substitution by $\mathrm{Cd}^{2+}$ in the catalytic center of PS II during photoactivation. Therefore, the increase in the $F_{0} / F_{v}$ ratio in both clones after $\mathrm{Cd}$ treatment suggested that the water-splitting apparatus of PS II was the primary site of action of $\mathrm{Cd}$. To better evaluate the activity of the photosynthetic apparatus under metal treatment, the Performance Index $\left(\mathrm{PI}_{\mathrm{ABS}}\right)$ was calculated (Zurek et al. 2014, Singh \& Prasad 2015). The $\mathrm{PI}_{\mathrm{ABS}}$ combines three independent functional steps of photosynthesis, such as the density of the reaction centers in the chlorophyll bed, the excitation energy trapping, and the conversion of excitation energy to electron transport into a single multi-parametric expression (Strasser et al. 2004). Consistent with Singh \& Prasad (2015), the higher decrease of the $\mathrm{Pl}_{A B S}$ indicated that in the Viglio clone the structure and the function of

Tab. 6 - Root, stem, leaf and total cadmium content $\left(\mathrm{mg}\right.$ plant $\left.{ }^{-1}\right)$, uptake ratio $\left(\mathrm{mg} \mathrm{mg}^{-1}\right)$, metal translocation index and phytoextraction efficiency $\left(\mathrm{mg} \mathrm{g}^{-1}\right)$ in plants of eucalypt hybrid clones treated in hydroponics for three weeks with $50 \mu \mathrm{M} \mathrm{CdSO}_{4}$. Data are mean values \pm standard error $(n=5)$. Different letters in the same column indicate significantly different values after $t$-test $(P \leq 0.05)$.

\begin{tabular}{|c|c|c|c|c|c|c|c|}
\hline \multirow{2}{*}{ Clone } & \multicolumn{4}{|c|}{ Cadmium content } & \multirow{2}{*}{$\begin{array}{l}\text { Uptake } \\
\text { ratio }\end{array}$} & \multirow{2}{*}{$\begin{array}{l}\text { Metal Trans- } \\
\text { location Index }\end{array}$} & \multirow{2}{*}{$\begin{array}{l}\text { Phytoextraction } \\
\text { efficiency }\end{array}$} \\
\hline & Root & Stem & Leaves & Total plant & & & \\
\hline Velino & $36.7 \pm 3.3^{\mathrm{a}}$ & $0.21 \pm 0.01^{a}$ & $0.011 \pm 0.002$ & $38.5 \pm 3.43^{a}$ & $0.21 \pm 0.01^{\mathrm{a}}$ & $0.049 \pm 0.005$ & $0.63 \pm 0.03^{a}$ \\
\hline Viglio & $21.9 \pm 2.3^{b}$ & $0.12 \pm 0.01^{b}$ & $0.006 \pm 0.001$ & $23.3 \pm 2.51^{b}$ & $0.12 \pm 0.01^{b}$ & $0.064 \pm 0.021$ & $0.36 \pm 0.06^{b}$ \\
\hline
\end{tabular}


PS II and the activity of the electron-transfer chain are more vulnerable to $\mathrm{Cd}$ compared to the Velino clone.

Metal content is an important parameter to investigate in candidate plants for phytoremediation, as the ability to absorb and accumulate metals in plant tissue is a basic trait for phytoextraction purposes. This trait is also considered a good indicator of the efficient detoxification and tolerance mechanisms (Pietrini et al. 2010). The results regarding the $\mathrm{Cd}$ content and distribution among organs of eucalypt clones are shown in Tab. 6 . The two eucalypt clones showed the same pattern of $\mathrm{Cd}$ distribution with a preferential metal accumulation in the roots. No differences between the two clones were observed with respect to $\mathrm{Cd}$ accumulation in the leaves and stems, whereas at the root level the Velino clone showed a higher $\mathrm{Cd}$ accumulation ability than the Viglio clone. Consequently, the total plant $\mathrm{Cd}$ content was higher in the clone Velino compared to the clone Viglio. It is worth pointing out that the high metal accumulation in the roots is a very useful trait to exploit in plants selected for water reclamation. In fact, in plant-based water decontamination systems the root biomass can be totally harvested, thus removing the absorbed metal. The accumulation of $\mathrm{Cd}$ in the roots of eucalypt plants is in agreement with findings by Gomes et al. (2012) and Fine et al. (2013).

To better highlight the ability of the two clones to extract $\mathrm{Cd}$ from the solution and accumulate it in plant tissues, the metal uptake ratio and the phytoextraction efficiency were evaluated (Tab. 6). In both cases, the data confirmed the greater performance of the Velino clone, since the $\mathrm{Cd}$ uptake ratio as well as the phytoextraction efficiency were far higher when compared to the Viglio clone. It is worth underlining that the metal uptake ratio of the Velino clone was slightly higher than that reported by lori et al. (2015) for willow clones exposed to the same $\mathrm{Cd}$ concentration in a similar experiment. With regard to the phytoextraction efficiency, it is noteworthy that, in this experiment, the value of this parameter was 10 times higher than that found by Wang et al. (2007) in plants of Elsholtzia splendens exposed to similar $\mathrm{Cd}$ concentrations in soil, and therefore with a different metal bioavailability. Nevertheless, the values for this parameter confirmed the higher bioaccumulation ability of the Velino clone.

Among the physiological processes associated with heavy metal tolerance in plants, the restriction of metal transport to the aerial parts has been highlighted in non hyperaccumulating plants (Lux et al. 2004, Gomes et al. 2012, lori et al. 2013). In fact, in leaves, $\mathrm{Cd}$ represents a very toxic agent, as it severely interferes with the photosynthetic processes (Pietrini et al. 2005). In this work, the ability of eucalypt plants to translocate the absorbed metal from root to the aerial parts was evaluated by the $\mathrm{Cd}$ translocation index (Tab. 6). Consistent with the limited literature present on the matter (Gomes et al. 2012, Fine et al. 2013), the two clones showed a low capability to translocate $\mathrm{Cd}$ in the aerial parts, and no differences were observed between the clones with respect to this physiological process.

\section{Conclusion}

In this work, an investigation into the biometric, physiological, and biochemical traits associated with the ability of eucalypt plants for the phytoremediation of $\mathrm{Cd}$ polluted waters was performed. The results obtained highlighted the notable ability of this plant species to tolerate and phytoextract the metal from the nutrient solution. Consistent with the little evidence present in the literature, eucalypt plants showed prevalent $\mathrm{Cd}$ accumulation in the root system with a low translocation to aerial organs. This finding has remarkable implications for phytoremediation, as the limitation of metal transport to leaves allows plants to better cope with metal exposure and to avoid a recycling of the metal from the rhizosphere to the soil top layers by leaf shedding. For the reclamation of metal polluted waters, the uppermost $\mathrm{Cd}$ accumulation in the roots is not to be considered a drawback, as in the water decontamination bio-systems the belowground plant biomass can be harvested at the end of the decontamination cycle, removing the metal accumulated by the roots. Given the notable tolerance of eucalypt plants to submersion and their adaptability to extremely wide pedoclimatic conditions, the results obtained in this work suggest that this plant species could be proposed for the reclamation of Cd-polluted waters.

\section{Acknowledgements}

Authors wish to thank Mr. Ermenegildo Magnani for his valuable technical assistance in metal content analysis.

\section{References}

Borghi M, Tognetti R, Monteforti G, Sebastiani L (2007). Responses of Populus $\times$ euramericana ( $P$. deltoides $\times P$. nigra) clone Adda to increasing copper concentrations. Environmental and Experimental Botany 61: 66-73. - doi: 10.1016/j.en vexpbot.2007.03.001

Cocozza C, Vitullo D, Lima G, Maiuro L, Marchetti M, Tognetti R (2014). Enhancing phytoextraction of Cd by combining poplar (clone "I-214") with Pseudomonas fluorescens and microbial consortia. Environmental Science and Pollution Research 21: 1796-1808. - doi: 10.1007/s11356-01 3-2073-3

Cocozza C, Trupiano D, Lustrato G, Alfano G, Vitullo $D$, Falasca A, Lomaglio T, De Felice $V$, Lima G, Ranalli G, Scippa S, Tognetti R (2015). Challenging synergistic activity of poplar-bacteria association for the $\mathrm{Cd}$ phytostabilization. Environmental Science and Pollution Research 22: 19546-19561. - doi: 10.1007/s11356-015-5097-z

Dan TV, Krishnaraj S, Saxena PK (2000). Metal tolerance of scented geranium (Pelargonium sp. 'Frensham'): effects of cadmium and nickel on chlorophyll fluorescence kinetics. International Journal of Phytoremediation 2: 91-104. doi: $10.1080 / 15226510008500032$

Dhillon KS, Dhillon SK, Thind HS (2008). Evaluation of different agroforestry tree species for their suitability in the phytoremediation of seleniferous soils. Soil Use and Management 24: 208-216. - doi: 10.1111/j.1475-2743.2008.00143.x

Fatta-Kassinos D, Kalavrouziotis IK, Koukoulakis $\mathrm{PH}$, Vasquez MI (2011). The risk associated with wastewater reuse and xenobiotics in the agroecological environment. Science of the Total Environment 409: 3555-3563. - doi: 10.1016/j.sci totenv.2010.03.036

Fine $\mathrm{P}$, Rathod PH, Beriozkin A, Mingelgrin U (2013). Uptake of cadmium by hydroponically grown, mature Eucalyptus camaldulensis saplings and the effect of organic ligands. International Journal of Phytoremediation 15: 585-601. - doi: 10.1080/15226514.2012.723061

Gallego SM, Pena LB, Barcia RA, Azpilicueta CE, Iannone MF, Rosales EP, Zawoznik MS, Groppa MD, Benavides MP (2012). Unravelling cadmium toxicity and tolerance in plants: insight into regulatory mechanisms. Environmental and Experimental Botany 83: 33-46. - doi: 10.101 6/j.envexpbot.2012.04.006

Gaudet M, Pietrini F, Beritognolo I, Iori V, Zacchini $M$, Massacci A, Scarascia Mugnozza $G$, Sabatti M (2011). Intraspecific variation of physiological and molecular response to cadmium stress in Populus nigra L. Tree Physiology 31: 1309-1318. - doi: 10.1093/treephys/tpro88

Gomes MP, Marques TCLLSM, Carneiro MMLC, Soares AM (2012). Anatomical characteristics and nutrient uptake and distribution associated with the Cd-phytoremediation capacity of Eucalyptus camaldulensis Dehnh. Journal of Soil Science and Plant Nutrition 12: 481-495. [online] URL: http://www.scielo.cl/scielo.php?pid=S071 8-95162012000300010\&script=sci_arttext

Gonzalez-Mendoza D, Espadasy GF, Santamara JM, Zapata-Perez O (2007). Multiple effects of cadmium on the photosynthetic apparatus of Avicennia germinans L. as probed by OJIP chlorophyll fluorescence measurements. Zeitschrift fur Naturforschung C 62: 265-272. - doi: 10.1515/znc-2007-3-418

Guidi Nissim W, Voicu A, Labrecque M (2014). Willow short-rotation coppice for treatment of polluted groundwater. Ecological Engineering 62: 102-114. - doi: 10.1016/j.ecoleng.2013.10.005

Harfouche A, Meilan R, Altman A (2014). Molecular and physiological responses to abiotic stress in forest trees and their relevance to tree improvement. Tree Physiology 34: 1181-1198. doi: 10.1093/treephys/tpuo12

Iori V, Pietrini F, Cheremisina A, Shevyakova NI, Radyukina N, Kuznetsov VV, Zacchini M (2013). Growth responses, metal accumulation and phytoremoval capability in Amaranthus plants exposed to nickel under hydroponics. Water, Air and Soil Pollution 224: 1450-1459. - doi: 10.1007/s11270-013-1450-3

Iori V, Pietrini F, Massacci A, Zacchini M (2015). Morphophysiological responses, heavy metal accumulation and phytoremoval ability in four willow clones exposed to cadmium under hydroponics. In: "Phytoremediation: Manage- 
ment of Environmental Contaminants" (Ansari AA, Gill SS, Gill R, Lanza GR, Newman L eds). Springer International Publishing, Switzerland, vol. I, pp. 87-98. - doi: 10.1007/978-3-319-103952_7

Iori V, Gaudet M, Fabbrini F, Pietrini F, Beritognolo I, Zaina G, Massacci A, Scarascia Mugnozza G, Zacchini M, Sabatti M (2016). Physiology and genetic architecture of traits associated with cadmium tolerance and accumulation in Populus nigra. Trees 30: 125-139. - doi: 10.1007/ soo468-015-1281-5

Krause GH, Weis E (1991). Chlorophyll fluorescence and photosynthesis: the basic. Annual Review of Plant Physiology 42: 313-349. - doi: 10.1146/annurev.pp.42.060191.001525

Kriedemann PF, Graham RD, Wiskich JT (1985). Photosynthetic dysfunction and in vivo chlorophyll a fluorescence from manganese-deficient wheat leaves. Australian Journal of Agriculture Research 36: 157-169. - doi: 10.1071/AR9850157

Krupa Z, Baszynski T (1995). Some aspects of heavy metals toxicity towards photosynthetic apparatus - direct and indirect effects on light and dark reactions: a review. Acta Physiologiae Plantarum 17: 177-190.

Kummerová M, Zezulka Š Králová K, Masarovičová E (2010). Effect of zinc and cadmium on physiological and production characteristics in Matricaria recutita. Biologia Plantarum 54: 308314. - doi: 10.1007/s10535-010-0053-8

Li Y, Liu J, Liu Y, Li X (2009). Effects of EDTA on mechanism of lead accumulation in Typha orientalis Presl. Bullettin of Environmental Contamination Toxicology 83: 553-557. - doi: 10.1007/ soo128-009-9787-4

Li S, Yang W, Yang T, Chen Y, Nia W (2015). Effects of cadmium stress on leaf chlorophyll fluorescence and photosynthesis of Elsholtzia argyi a cadmium accumulating plant. International Journal of Phytoremediation 17: 85-92. doi: $10.1080 / 15226514.2013 .828020$

Lichtentaler HK (1987). Chlorophyll and carotenoids pigments of photosynthetic biomembranes. Methods in Enzymology 148: 350-82. doi: 10.1016/0076-6879(87)48036-1

Lu Q, He ZL, Graetz DA, Stoffella PJ, Yang X (2011). Uptake and distribution of metals by water lettuce (Pistia stratiotes L.). Environmen- tal Science and Pollution Research 18: 978-986. - doi: 10.1007/s11356-011-0453-0

Lux A, Opatrná J, Greger M (2004). Differences in structure of adventitious roots in Salix clones with contrasting characteristics of cadmium accumulation and sensitivity. Physiologia Plantarum 120: 537-545. - doi: 10.1111/j.0031-9317.20 04.0275.x

Mallick N, Mohn FH (2003). Use of chlorophyll fluorescence in metal-stress research: a case study with the green microalga Scenedesmus. Ecotoxicology and Environmental Safety 55: 64-69. - doi: 10.1016/S0147-6513(02)00122-7

Mughini G, Alianiello F, Benedetti A, Mughini Gras L, Gras MA, Salvati L (2013). Clonal variation in growth, arsenic and heavy metal uptakes of hybrid Eucalyptus clones in a Mediterranean environment. Agroforestry Systems 87: 755-766. - doi: 10.1007/s10457-013-9594-0

Pietrini F, lannelli MA, Montanari R, Bianconi D, Massacci A (2005). Cadmium interaction with thiols and photosynthesis in higher plants. In: "Advances in Plant Physiology" (Hemantaranjan A ed). Scientific Publishers, Jodhpur, India, vol. 8, pp. 313-326. [online] URL: http://s3. amazonaws.com/academia.edu.documents/415 71558

Pietrini F, Zacchini M, Iori V, Pietrosanti L, Bianconi D, Massacci A (2010). Screening of poplar clones for cadmium phytoremediation using photosynthesis, biomass and cadmium content analyses. International Journal of Phytoremediation 12: 105-120. - doi: 10.1080/15226510902767 163

Pietrini F, lori V, Bianconi D, Mughini G, Massacci A, Zacchini M (2015). Assessment of physiological and biochemical responses, metal tolerance and accumulation in two eucalypt hybrid clones for phytoremediation of cadmium-contaminated waters. Journal of Environmental Management 162: 221-231. - doi: 10.1016/j.jenvman.20 15.07.053

Sharma RK, Agrawal M, Marshall FM (2008). Heavy metal ( $\mathrm{Cu}, \mathrm{Zn}, \mathrm{Cd}$ and $\mathrm{Pb}$ ) contamination of vegetables in urban India: a case study in Varanasi. Environmental Pollution 154: 254-263. - doi: 10.1016/j.envpol.2007.10.010

Singh S, Prasad SM (2015). IAA alleviates Cd toxicity on growth, photosynthesis and oxidative damages in eggplant seedlings. Plant Growth Regulation 77: 87-98. - doi: 10.1007/s10725-0150039-9

Stoláriková $M$, Vaculík $M$, Lux $A$, Di Baccio $D$, Minnocci A, Andreucci A, Sebastiani L (2012). Anatomical differences of poplar (Populus $\times$ euramericana clone 1-214) roots exposed to zinc excess. Biologia 67: 483-489. - doi: 10.2478/s 11756-012-0039-4

Strasser R, Tsimilli-Michael M, Srivastava A (2004). Analysis of the chlorophyll a fluorescence transient. In: "Chlorophyll a fluorescence. Advances in photosynthesis and respiration" (Papageorgiou G, Govindjee eds). Springer, Netherlands, pp. 321-362. - doi: 10.1007/97 8-1-4020-3218-9_12

Vassilev A, Berova M, Zlatev Z (1998). Influence of $\mathrm{Cd}^{2+}$ on growth, chlorophyll content, and water relations in young barley plants. Biologia Plantarum 41: 601-606. - doi: 10.1023/A:1001856 819797

Vassilev A, Perez-Sanz A, Semane B, Carleer R, Vangronsveld J (2005). Cadmium accumulation and tolerance of two Salix genotypes hydroponically grown in presence of cadmium. Journal of Plant Nutrition 28: 2159-2177. - doi: 10.1080/01904160500320806

Wang FY, Lin XG, Yin R (2007). Role of microbial inoculation and chitosan in phytoextraction of $\mathrm{Cu}, \mathrm{Zn}, \mathrm{Pb}$, and $\mathrm{Cd}$ by Elsholtzia splendens - a field case. Environmental Pollution 147: 248255. - doi: 10.1016/j.envpol.2006.08.005

Zacchini M, Pietrini F, Scarascia-Mugnozza G, lori V, Pietrosanti L, Massacci A (2009). Metal tolerance, accumulation and traslocation in poplar and willow clones treated with cadmium in hydroponics. Water, Air and Soil Pollution 197: 23-34. - doi: 10.1007/s11270-008-9788-7

Zhivotovsky OP, Kuzovkina JA, Schulthess CP, Morris T, Pettinelli D, Ge M (2011). Hydroponic screening of willows (Salix L.) for lead tolerance and accumulation. International Journal of Phytoremediation 13: 75-94. - doi: 10.1080/ 15226511003671361

Zurek G, Rybka K, Pogrzeba M, Krzyzak J, Prokopiuk K (2014). Chlorophyll a fluorescence in evaluation of the effect of heavy metal soil contamination on perennial grasses. PLOS One 9: e91475. - doi: 10.1371/journal.pone.0091475 